\title{
EFFECT OF GRAIN BOUNDARIES ON THE ELECTRON WORK FUNCTION OF ULTRAFINE GRAINED ALUMINUM
}

\author{
T.S. Orlova ${ }^{1}$, A.V. Ankudinov ${ }^{1}$, A.M. Mavlyutov ${ }^{2}$ and N.N. Resnina ${ }^{3}$ \\ ${ }^{1}$ loffe Institute, Russian Academy of Sciences, Politekhnicheskaya str. 26, St. Petersburg, 194021 Russia \\ 2Saint Petersburg National Research University of Information Technologies, \\ Mechanics and Optics, Kronverksky Pr. 49, St. Petersburg 197101, Russia \\ ${ }^{3}$ Saint Petersburg State University, Universitetskaya nab. 7/9, St. Petersburg, 199034, Russia
}

Received: May 08, 2018

\begin{abstract}
The electron work function (EWF) of ultrafine grained (UFG) aluminum structured by high pressure torsion (HPT) has been investigated. For the first time, the dependence of the EWF on the specific length of grain boundaries (or the grain size) for UFG AI has been obtained. The change of average grain size was achieved by short term annealing of HPT-processed aluminum at different temperatures from the range $90-400{ }^{\circ} \mathrm{C}$. It has been shown that the state of grain boundaries (GBs) affects the magnitude of the EWF. It has been found that the transformation of GBs due to annealing at $90{ }^{\circ} \mathrm{C}$ from a nonequilibrium to more equilibrium state while maintaining the specific length of GBs and their average misorientation is accompanied by a decrease in average GB specific energy by $0.3 \mathrm{~J} \mathrm{~m}^{-2}$. This transition provides a sharp increase in the EWF of the UFG Al by $0.25 \mathrm{eV}$.
\end{abstract}

\section{INTRODUCTION}

Electron work function (EWF) is a fundamental physical parameter of metallic surface, it is important characteristic to understand a wide range of surface phenomena, such as catalytic behavior, adsorption, surface segregation, surface corrosion, the Volta potential and others [1].

Earlier it was shown that electrons in grain boundaries (GBs) are more active and the EWF decreases with increasing the GB density for polycrystalline $\mathrm{Cu}$ and $\mathrm{Al}$ with grain sizes from 0.04 $\mathrm{mm}$ to $0.6 \mathrm{~mm}$ [2]. The decrease in the EWF in the vicinity of GBs is due to lattice distortions and GB defects, the main of which are dislocations [3].

Due to the high density of GBs, ultrafine grained (UFG, grain size $100 \mathrm{~nm}<d<1000 \mathrm{~nm}$ ) and nanocrystalline (NC, $d<100 \mathrm{~nm}$ ) materials possess a number of unique mechanical, physical, and chemical properties. It has been recently found that nanostructuring of some metals leads to a significant decrease in their EWF [4-8]. This opens the possibility of using nanostructured metals as materials for cathodes in electronic and ionic devices, including cold cathodes of gas-discharge devices with glow discharge [9].

A decrease in the EWF in metals structured by severe plastic deformation can be caused not only by an increase in the fraction of GBs due to decreasing the average grain size, but also by the formation of the so-called nonequilibrium state of the grain boundaries (here and further, the nonequilibrium state of GBs means their state with excess energy) in the NC structure $[8,10,11]$, as it was experimentally observed, for example, for $\mathrm{NC} \mathrm{Ni}$ [8]. For Al with NC and UFG structures, the influence of grain size on EWF, as well as the influence of the nonequilibrium state of GBs remained unknown, whereas it is in such states that aluminum and its

Corresponding author:T.S. Orlova, e-mail: orlova.t@mail.ioffe.ru

(C) 2018 Advanced Study Center Co. Ltd. 
Table 1. The parameters of the microstructure of Al samples after HPT processing and subsequent annealing [12,13]: $d_{a v}$ is the average grain size, $f_{\geq 15}$ is the percentage of GBs with the misorientation angle $\geq 15^{\circ}, \theta_{a v}$ is the average angle of GB misorientations, and $L_{\text {dis }}$ is the dislocation density.

\begin{tabular}{lllll}
\hline Sample & $d_{a v}, \mathrm{~nm}$ & $f_{z 15}, \%$ & $\theta_{a v}{ }^{\circ}$ & $L_{d i s}, \mathrm{~m}^{-2}$ \\
\hline Al_HPT & $810 \pm 9$ & 77 & 33 & $2 \cdot 10^{12}$ \\
Al_HPT_90 & $850 \pm 11$ & 78 & 32 & $7 \cdot 10^{11}$ \\
Al_HPT_130 & $1130 \pm 17$ & 80 & 33 & $6 \cdot 10^{11}$ \\
Al_HPT_150 & $1160 \pm 9$ & 76 & 31 & $<6 \cdot 10^{11}$ \\
Al_HPT_200 & $1090 \pm 18$ & 72 & 31 & $<6 \cdot 10^{11}$ \\
Al_HPT_400 & $7200 \pm 525$ & 31 & 15 & $<6 \cdot 10^{11}$ \\
\hline
\end{tabular}

alloys demonstrate unique functional properties and have a high potential for different applications.

In the present work, we investigated the effect of GBs in UFG Al structured by high pressure torsion on the electron work function. Particular attention was paid to the separation of the effects of the specific length of the GBs and their state on the electron work function in aluminum.

\section{MATERIALS AND EXPERIMENTAL PROCEDURES}

The commercial purity aluminum A5E (min. 99.5 wt.\% Al) further denoted as $\mathrm{Al}$ was chosen as the material of this study. To form UFG structure the initially coarse grained (CG) Al disks of the diameter $20 \mathrm{~mm}$ and thickness $2 \mathrm{~mm}$ were subjected to high pressure torsion (HPT) under a hydrostatic pressure of $6 \mathrm{GPa}$ to 10 revolutions at RT. After HPT processing the true strain at the distance of $5 \mathrm{~mm}$ from disk center was $e^{\sim 6.6}$. More information about HPT processing can be found in [12]. Then the samples were annealed at different annealing temperatures from the range $90-400^{\circ} \mathrm{C}$ for $1 \mathrm{~h}$. Further, the samples after HPT processing without subsequent annealing are denoted as Al_HPT, and the samples after HPT processing with subsequent annealing are denoted as Al_HPT_T ${ }_{A N}$, where $T_{A N}$ is the annealing temperature in ${ }^{\circ} \mathrm{C}$. The original $\mathrm{CG}$ sample is denoted as Al_CG (CG - coarse-grained).

The investigation of microstructure of the samples under study was performed by electron backscatter diffraction (EBSD), X-ray diffraction (XRD) and transmission electron microscopy (TEM) in our previous works $[13,14]$. For all the studied samples the structural characterization was performed in a sample area at a distance of $5 \mathrm{~mm}$ from the disk center. The main microstructural parameters such as the average grain size $d_{a v}$, the fraction of grain boundaries $f_{\geq 15}$ with the misorientation angle $\geq 15^{\circ}$ (HAGBs - high angle grain boundaries), the dislocation density $L_{\text {dis }}$ are presented in Table 1 .

For all the studied samples, the electron work function was investigated by the scanning Kelvin probe microscopy (SKPM) using an atomic force microscope (AFM) Ntegra Aura (NT-MDT SI). A potential difference $V$ between the sample surface and the cantilever tip was measured. In our case, platinum coated cantilevers were used. Topography and SKPM signal $(V$ measurements were performed over an area of $25 \times 25 \mu \mathrm{m}^{2}$. As a result, two-dimensional (2D) images of the sample surface topography and maps of the SKPM signal distribution over the same surface were obtained. The SKPM signal averaged over the scanned surface $\left(V_{a v}\right)$ was determined for each studied sample.

The work function $\varphi$ of the studied samples was defined as:

$\varphi=\varphi_{c}-\left|e V_{a v}\right|$,

where $\varphi_{c}$ is the EWF of the cantilever material, $\mathrm{Pt}$ in our case. For determining the absolute values of the electron work function, the reference value of $5.3 \mathrm{eV}$ for platinum [15] was taken into account.

To study the samples by atomic force microscopy the surface of the samples was treated using grinder/polisher machine (Buehler the EcoMet 250 Pro). Mechanical grinding was carried out using sanding papers with a gradual decrease in grit. Subsequent polishing was performed with diamond suspensions. When changing the suspension, the polishing direction on the sample surface was also changed. The final surface treatment after mechanical polishing was carried out by chemical etching immediately before measuring the work function. The surface of the samples was etched by a $30 \% \mathrm{NaOH}$ solution at a temperature of $35-40^{\circ} \mathrm{C}$ for $20 \mathrm{~s}$. After etching, the surface of the samples was washed in a flow of distilled water and wiped with $70 \% \mathrm{HNO}_{3}$ 
(a)

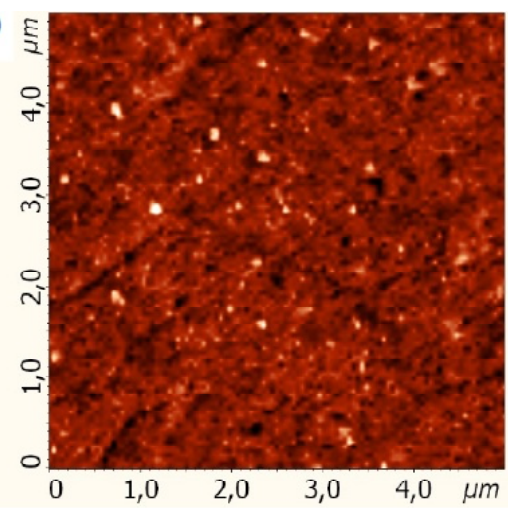

(c)

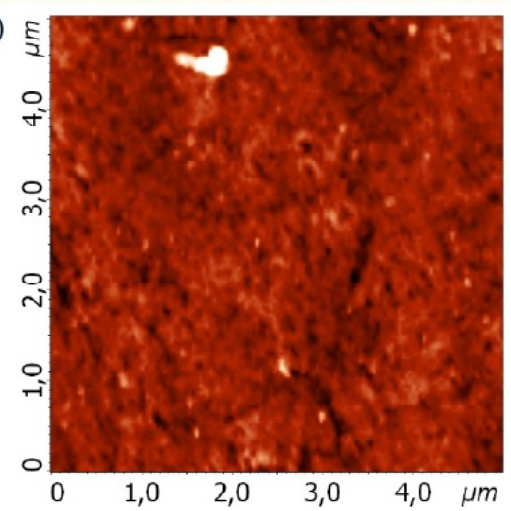

E. (b)

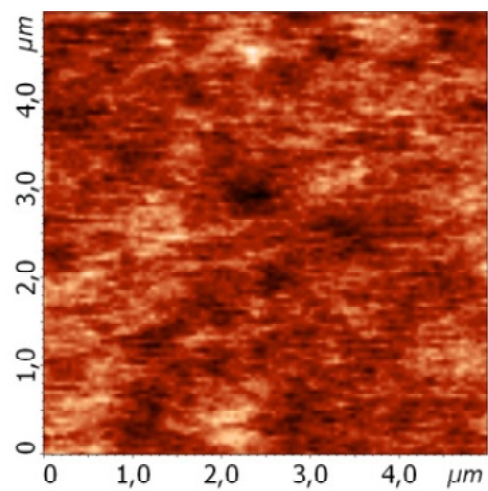

E[(d)

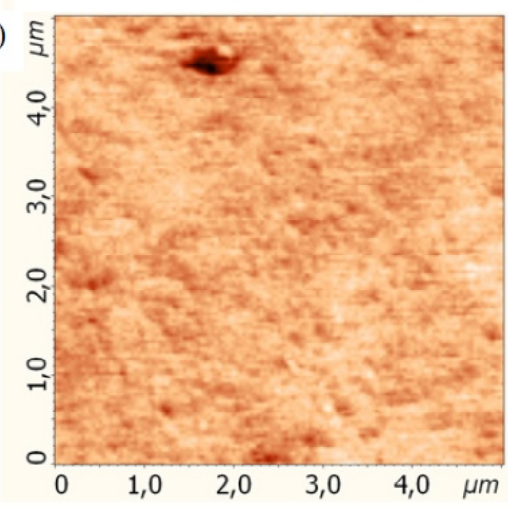

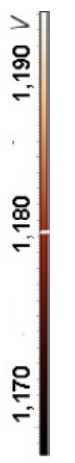

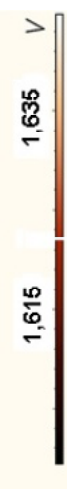

Fig. 1. AFM topography images of the surface $(a, c)$ and the corresponding maps of the distribution of the SKPM signal over this surface (b, d) for samples of Al in the initial CG state $(a, b)$ and in UFG state obtained by HPT processing $(c, d)$.

solution, then washed again with distilled water and dried.

The heat released during heating was studied using a METTLER TOLEDO 822e differential scanning calorimeter (DSC). Samples weighting 30-40 mg were heated from 20 to $300^{\circ} \mathrm{C}$ at $50 \mathrm{~K} / \mathrm{min}$ ramp rate. During the first heating, heat release peaks were recorded on the calorimetric curves. The temperature of the peaks was determined by the method of secant. The amount of released energy was determined as the area under the calorimetric peak using the STARe program. After the first heating, the sample was cooled to room temperature and reheated at the same ramp rate to ensure that the heat release process was irreversible. No heat release peaks were detected during the reheating process.

It should be noted that EWF and DSC measurements were performed on a sample area located at a distance of $5 \mathrm{~mm}$ from the disk center.

\section{RESULTS AND DISCUSSION}

Typical AFM image of the surface topography and the map of the distribution of the difference potential between the sample surface and the cantilever tip for Al in the initial coarse-grained and in the UFG states obtained by the HPT are shown in Fig. 1. HPT processing of Al leads to a significant increase in the $V_{a v}$ value by $\sim 0.44 \mathrm{~V}$ and, hence, to decrease in $\operatorname{EWF}(\varphi)$ by $0.44 \mathrm{eV}$. According to Eq. (1), the EWF of aluminum is equal to $\sim 3.68 \mathrm{eV}$ for the UFG state obtained by HPT, and $\sim 4.12 \mathrm{eV}$ for the $\mathrm{CG}$ state. The value of $\sim 4.12 \mathrm{eV}$ for the CG state is in good agreement with the literature data for unstructured $\mathrm{Al}$ (EWF of Al is 4.06-4.26 eV [15]). The obtained decrease of EWF in UFG Al is comparable to a decrease of the EWF in $\mathrm{Ni}[8]$ and $\mathrm{Al}-6 \% \mathrm{Mg}$ alloy [9] after their processing by HPT. Usually, a decrease in the EWF after deformation is associated with the introduction of defects, mainly, dislocations and increase in the GB density. In our case, as shown by microstructural studies, the HPT processing resulted in a significant decrease in grain size, the grain interior in the obtained UFG structure was practically free from dislocations, and the integral dislocation density measured by XRD was rather low $\left(\sim 4 \cdot 10^{-12} \mathrm{~m}^{-2}\right)$ and mostly attributed to the regions of grain boundaries, the most of GBs are high-angle grain boundaries (Table 1) [13]. Thus, the observed significant decrease of the EWF is mainly due to the increase in the GB density. 


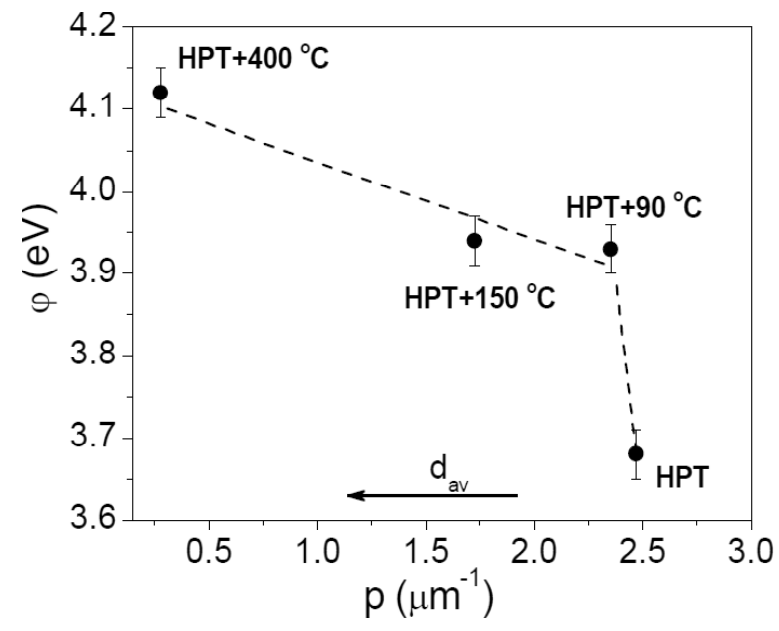

Fig. 2. Dependence of the electron work function on the specific length of grain boundaries for Al samples subjected to HPT processing and subsequent annealing for $1 \mathrm{~h}$ at various temperatures.

Then the Al_HPT samples were annealed for $1 \mathrm{~h}$ at various temperatures $T_{A N}$. With an increase of $T_{A N}$ from 90 to $200{ }^{\circ} \mathrm{C}$, the grain size increased slightly, and then grew to CG size at $T_{A N}=400{ }^{\circ} \mathrm{C}$ (Table 1). Similarly to [8], the specific length of grain boundaries $p$ (the total length of GBs per unit area) can be estimated from the cubic shape of the grain as $p=2 / d$. Fig. 2 shows the dependence of the EWF value on the parameter $p$, which changes as a result of annealing. As seen in Fig. 2, the smallest electron work function belongs to $\mathrm{Al}$ in UFG state obtained by HPT processing. Then annealing at 90 ${ }^{\circ} \mathrm{C}$ results in a sharp increase of $\varphi$ value by $0.25 \mathrm{eV}$, while the value of the parameter $p$ (or grain size $d$ ) is almost unchanged. As shown by microstructural studies (Table 1), as a result of the annealing of Al_HPT samples at $90^{\circ} \mathrm{C}$, the grain size remains almost unchanged, and the distribution of GBs over misorientations is preserved. The only variable parameter is the dislocation density (Table 1), and the latter is mainly attributed to the GB regions, since the grains are practically free from dislocations both before and after annealing at $T_{A N}=90^{\circ} \mathrm{C}$ [13]. According to [13], during such annealing, GBs relax from a nonequilibrium state to a more equilibrium one with a decrease in the dislocation density in them. It was shown in [13] that such a change in the state of the GBs leads to a significant decrease in their specific electrical resistivity.

As noted above, nonequilibrium state of a GB means its state with excess energy [16,17]. Such a nonequilibrium state of a GBs can be caused by the presence of external (lattice) dislocations [18] or structural disordering in the grain boundary [19],

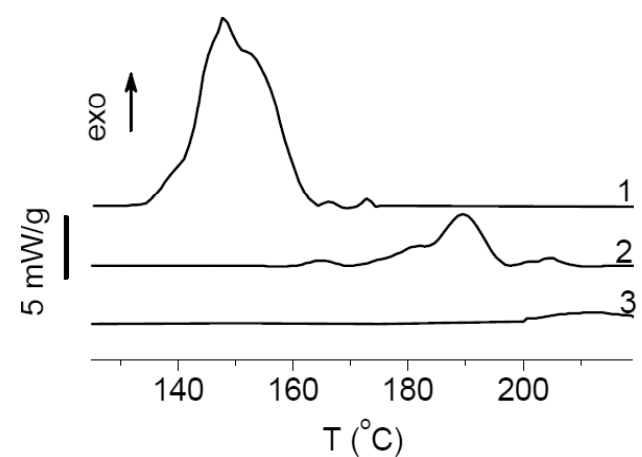

Fig. 3. Differential scanning calorimetric curves obtained during the first heating of Al samples subjected to HPT processing (1) and subsequent annealing for $1 \mathrm{~h}$ at $90^{\circ} \mathrm{C}(2)$ and $200^{\circ} \mathrm{C}(3)$.

which leads to elastic distortions of the crystalline lattice near the GB. Nonequilibrium GB structure was shown to be typical for bulk nanostructured materials processed by severe plastic deformation and to largely determine their properties [10].

To confirm a change of the average energy of GBs due to annealing, we measured the released energy in the samples before and after annealing by the DSC method. The differential scanning calorimetry curves are shown in Fig. 3. Exothermic peaks during heating at a rate of $50 \mathrm{~K} / \mathrm{min}$ are observed for UFG Al before and after annealing at $T_{\mathrm{AN}}=90^{\circ} \mathrm{C}$, however, the released energy per unit mass in Al_HPT_90 sample is significantly less than in Al_HPT sample. The onset temperature of the exothermic peak is equal to $T_{\text {on }} \approx 135{ }^{\circ} \mathrm{C}$ for the unannealed sample Al_HPT and decreases with increasing $T_{A N}$ (Table 2). As a rule, when the accumulated deformation energy in a material increases, the onset temperature of its release decreases and the amount of released energy increases $[20,21]$.

As a result of annealing of Al_HPT sample at $90^{\circ} \mathrm{C}$, the energy accumulated during HPT processing is reduced by $\Delta F=0.39 \mathrm{~J} \mathrm{~g}^{-1}$ (Fig. 3, Table 2). Taking into account the fact that after annealing at $90{ }^{\circ} \mathrm{C}$ the grain size as well as the distribution of GBs on misorientation practically did not change,

Table 2. Results of DSC studies. $F$ is the amount of released heat, $T_{\text {on }}$ is the temperature of the onset of heat release.

\begin{tabular}{lll}
\hline Sample & $F\left(\mathrm{~J} \mathrm{~g}^{-1}\right)$ & $\left.T_{\text {on }}{ }^{\circ} \mathrm{C}\right)$ \\
\hline Al_HPT & 0.55 & 135 \\
Al_HPT_90 & 0.16 & 159 \\
Al_HPT_200 & 0.1 & $\sim 202$ \\
\hline
\end{tabular}


the released energy can be attributed to a GB structure rearrangement accompanied by a decrease in the dislocation density. Then the excess energy per unit area of GBs in the UFG Al_HPT samples before annealing can be estimated as:

$$
\Delta \gamma=\Delta F / S_{G B}
$$

where $S_{G B}$ is the GB area per unit mass. Based on the cubic shape of the grains the area of GBs per unit mass can be determined as:

$$
S_{G B}=3 / d_{a v} \rho,
$$

where $d_{a v}$ is the average grain size, $\rho=2.7 \mathrm{~g} \mathrm{~cm}^{-3}$ is the density of Al. Taking into consideration that $d_{a v}=810-850 \mathrm{~nm}$ for Al_HPT and AI_HPT_90 (Table 1 ), the released excess energy per unit area of GBs is $\Delta \gamma=0.29 \pm 0.01 \mathrm{~J} \mathrm{~m}^{-2}$. The obtained value of $\Delta \gamma$ is in good agreement with the data of [22]. It was shown in [22] by computer simulations that the relaxation of a tilt boundary with misorientation in a wide range of $10-45^{\circ}$ leads to a decrease of its energy from $\sim 0.6 \mathrm{~J} \mathrm{~m}^{-2}$ to $0.2-0.45 \mathrm{~J} \mathrm{~m}^{-2}$, depending on the degree of the grain boundary relaxation. Annealing at a higher temperature $T_{A N}=200^{\circ} \mathrm{C}$ leads to a further, but already slight change in the released energy (Table 2), that indicates that annealing at $90^{\circ} \mathrm{C}$ for $1 \mathrm{~h}$ provides significant relaxation of GBs.

Then, a gradual increase in the EWF occurs when the annealing temperature further increases from 90 to $400{ }^{\circ} \mathrm{C}$ (Fig. 2). UFG and NC metals with a high density of grain boundaries can be considered in the framework of the two-phase model [8,23], according to which they consist of two phases: the grain and grain-boundary phases, each of which has its own value of the EWF. The grain phase has the electron work function value typical for the single crystalline material, while the grain-boundary phase is characterized by a lower value of the EWF [24,25].

According to the spot theory [26], the electron work function of NC or UFG material can be defined as:

$$
\varphi=\varphi_{0} A_{G}+\varphi_{G B} A_{G B},
$$

where $\varphi_{0}$ and $\varphi_{\mathrm{GB}}$ are the electron work functions of the grain body and GBs, respectively; $A_{G}$ and $A_{G B}$ are the specific areas of the grain and grain boundary phases on the emitting surface, respectively.

The specific area of the grain boundary phase can be represented as:

$$
A_{G B}=\rho \delta,
$$

where $\delta$ is the width of the grain boundary phase. For nanostructured metals, the physical width of the grain boundary phase $\delta$ exceeds the crystallographic width of the GBs by an order of magnitude and is about $10 \mathrm{~nm}[17,27]$. Estimation of the physical width of the GBs in UFG Al, structured by the HPT, was carried out earlier in [14] and the value $\delta=8-9 \mathrm{~nm}$ was obtained. As seen, after initial sharp increase of $\varphi$ value in the range $p=2.35$ 2.47, with further decreasing the parameter $p$ the dependence $\varphi(p)$ becomes close to linear (Fig. 2), that is consistent with expressions (4) and (5).

The sharp increase of $\varphi$ value in the range $p=2.35$ 2.47 appear to be due to both a change in the $\varphi_{G B}$ value and a change in the physical width $\delta$ of the GBs when they are rearranged from a non-equilibrium to a more equilibrium state (to a state with lower energy).

\section{CONCLUSIONS}

In this paper, for the first time, the dependence of the electron work function on the specific length of the GBs for UFG Al structured by HPT has been determined. It was shown that the structuring of $\mathrm{Al}$ by the HPT leads to a significant decrease of the EWF by approximately $10 \%$. Such decrease results from both a decrease in the specific length of GBs and to a large extent from their non-equilibrium state (state with excess energy). It has been found that annealing at $90{ }^{\circ} \mathrm{C}$ leads to a decrease in the average specific energy of the GBs by $\sim 0.3 \mathrm{~J} \mathrm{~m}^{-2}$ without any significant change in their density. Such a transition of the GB state from a nonequilibrium state to a more equilibrium one is accompanied by an increase in the electron work function by a value of $0.25 \mathrm{eV}$.

\section{ACKNOWLEDGEMENTS}

AMM thanks the Ministry of Education and Science of the Russian Federation for its support (Project No 3.3194.2017/4.6).

\section{REFERENCES}

[1] J. Wang and S.Q. Wang // Surf. Sci. 630 (2014) 216.

[2] W. Li and D.Y. Li // Surf. Rev. Let. 11 (2004) 173.

[3] N.A. Shipitsa, A.L. Zharin, D.I. Saroka and A.A. Dmitrovich // Phys. Mezomech. 7 S1 (2004) 218, In Russian.

[4] R.R. Mulyukov and Y.M. Yumaguzin // Doklady Physics 49 (2004) 730.

[5] R.R. Mulyukov // J. Vacuum Sci. Tech. B 24 (2006) 1061. 
[6] I.R. Nabiullin, A.N. Lachinov, R.K. Khisamov and R.R. Mulyukov // Physics of the Solid State 54 (2012) 446.

[7] A.A. Samigullina, R.K. Khisamov and R.R. Mulyukov // Letters on Materials 2 (2012) 134.

[8] R.K. Khisamov, I.M. Safarov, R.R. Mulyukov and Y.M. Yumaguzin // Physics of the Solid State 55 (2013) 1.

[9] R.K. Khisamov, K.S. Nazarov, I.M. Safarov, I.I. Musabirov, Y.M. Yumaguzin and R.R. Mulyukov // Materials Physics and Mechanics 33 (2017) 161.

[10] A.A. Nazarov and R.R. Mulyukov, In: Handbook of nanoscience, engineering and technology, ed. By W. Goddard, D. Brenner, S. Lyshevski and $\mathrm{G}$. lafrate (CRC Press, 2002).

[11] N.I. Noskova and R.R. Mulyukov, Submicrocrystalline and Nanocrystalline Metals and Alloys (Ural. Otd. Ross. Akad. Nauk, Ekaterinburg, 2003), In Russian.

[12] A.P. Zhilyaev and T.G. Langdon // Prog. Mat. Sci. 53 (2008) 893.

[13] T.S. Orlova, A.M. Mavlyutov, A.S. Bondarenko, I.A. Kasatkin, M.Yu. Murashkin and R.Z. Valiev // Phil. Mag. 96 (2016) 2429.

[14] A.M. Mavlyutov, A.S. Bondarenko, M.Yu. Murashkin, E.V. Boltynjuk, R.Z. Valiev and T.S. Orlova // JALCOM698 (2017) 539.

[15] V.S. Fomenko, Emission Properties of Materials (Naukova Dumka, Kiev, 1981), In Russian.
[16] O.A. Kaibyshev and R.Z. Valiev, Grain boundaries and properties of metals (Moscow, Metallurgia Publ., 1987).

[17] R.R. Mulyukov // Rossiyskiye Nanotekhnologii 2 (2007) 38, In Russian.

[18] R.Z. Valiev, V.Yu. Gertsman and O.A. Kaibyshev // Phys. Status Solidi A 97 (1986) 11.

[19] A.E. Romanov, A.L. Kolesnikova, T.S. Orlova, I. Hussainova, V.E. Bougrov and R.Z. Valiev // Carbon 81 (2015) 223.

[20] L.M. Clarebrough, M.E. Hargreaves and G.W. West // Proc. Roy. Soc. A 232 (1955) 252.

[21] S.R. Agnew, B.R. Elliott, C.J. Youngdahl, K.J. Hemker and J.R. Weertman // Mat. Sci. Eng. A 285 (2000) 391.

[22] A.V. Weckman // Izvestiya Tomskogo Politekhnicheskogo Universiteta 313 (2008) 96, In Russian.

[23] R.R. Mulyukov // Rev. Adv. Mater. Sci. 11 (2006) 122.

[24] R.R. Mulyukov, E.A. Litvinov, L.R. Zubairov, Y.M. Yumaguzin and V.A. Ivchenko // Physica B 324 (2002) 329.

[25] E.A. Litvinov, R.R. Mulyukov, L.R. Zubairov, Y.M. Yumaguzin and V.A. Ivchenko // Technical Physics 49 (2004) 758.

[26] K.I. Ibragimov and V.A. Korol'kov, Electron Work Function in Physicochemical Research (Intermet Inzhiniring, Moscow, 2002), In Russian.

[27] R.Z. Valiev, R.R. Mulyukov and V.V. Ovchinnikov // Phil. Mag. Lett. 62 (1990) 253. 